\title{
Prospecção Tecnológica na Área de Paisagens Sonoras (Soundscape)
}

\author{
Technological Prospection in the Area of Soundscape
}

\author{
Jordana Teixeira da Silva ${ }^{1}$ \\ João Paulo Lima Santos ${ }^{2}$ \\ Maria Lucia Gondim da Rosa Oiticica \\ Edilson Ponciano de Lima² \\ ${ }^{1}$ Instituto Federal de Alagoas, Palmeira dos Índios, AL, Brasil \\ ${ }^{2}$ Universidade Federal de Alagoas, Maceió, AL, Brasil
}

\begin{abstract}
Resumo
O campo de estudo em paisagem sonora (soundscape), que considera a percepção do usuário ao ambiente acústico dentro de um contexto, está ganhando força nos últimos anos, em função da necessidade em superar a abordagem do gerenciamento dos ambientes urbanos baseados apenas em políticas de controle do ruído. Com isso, houve um aumento no número de publicações científicas e tecnológicas relacionadas ao soundscape. O presente trabalho visa a apresentação de cenários prospectivos ligados ao desenvolvimento de tecnologias soundscape nas bases de patentes e científicas. Os resultados da prospecção tecnológica em bases de patentes indicam que os desenvolvimentos ligados a temática soundscape são relativamente novos, tendo em vista que $44,4 \%$ dos depósitos de patentes estão concentrados nos últimos 5 anos. A produção científica atingiu o percentual máximo em 2018, que coincidiu com a publicação da segunda parte da norma ISO 12913:2, a qual trata de procedimentos para coleta de dados para avaliação da paisagem sonora.
\end{abstract}

Palavras-chave: Soundscape. Paisagem sonora. Prospecção.

\begin{abstract}
The field of soundscape study, which considers the user's perception of the acoustic environment within a context, has been gaining strength in recent years, due to the need to overcome the approach to the management of urban environments based only on noise control policies. As a result, there has been an increase in the number of scientific and technological publications related to soundscape. The present work aims to present prospective scenarios linked to the development of soundscape on the basis of patents and science. Results of the technology prospecting in patent databases indicate that the developments related to soundscape themes are relatively new, considering that $44.4 \%$ of the patent deposits are concentrated in the last 5 years. Scientific production peaked in 2018, which coincided with the publication of the second part of the ISO 12913:2 standard, which deals with data collection procedures for assessing the soundscape.
\end{abstract}

Keywords: Soundscape. Technology. Prospection.

Área Tecnológica: Prospecção Tecnológica. 


\section{Introdução}

Em função do desenvolvimento industrial e tecnológico, diversas fontes de poluição ambiental têm provocado uma série de danos ao meio ambiente e à qualidade de vida do homem. Em virtude do aumento dos problemas provocados pelo ruído urbano, a poluição sonora tornou-se um dos principais agravantes para a saúde do homem, conduzindo à deterioração da qualidade de vida nas cidades, perdendo apenas para a poluição do ar e da água (HARVIE et al., 2019; WHO, 1999).

No decorrer dos anos, a avaliação do som era baseada nos aspectos epidemiológicos do ruído, com a implantação de políticas internacionais ambientais com o propósito de controle do ruído (KANG et al., 2016). Nesse sentido, a partir da abordagem quantitativa do som, países europeus foram pioneiros quanto às medidas e legislações voltadas para a mitigação do ruído, a exemplo do Green Paper $^{1}$ (ZIMMERMAN, 2011) e da Diretiva Europeia ${ }^{2}$ 2002/49/CE (HOLTZ, 2012). No entanto, alguns estudos apontam que a redução dos níveis sonoros não necessariamente resulta no aumento da percepção positiva e qualidade do ambiente acústico (CAIN et al., 2013; ALETTA et al., 2016).

A abordagem quantitativa do ruído nas cidades é direcionada para avaliação dos ambientes acústicos e comparação com valores de referência de níveis sonoros presentes nas normas técnicas e legislações (GOZALO et al., 2015). Cálculos, medições dos níveis sonoros e simulações computacionais podem ser realizados para a elaboração de mapas acústicos, que ilustram a configuração do ruído ambiental em uma determinada área, de forma que podem ser utilizados no gerenciamento do ruído nas cidades, identificando áreas onde existe excesso de ruído, para auxiliar no planejamento urbano.

A partir da década de 1970, esta abordagem começou a ser questionada por um grupo de pesquisadores coordenados por Murray Schaffer, professor, escritor e músico canadense. Schaffer e seus colegas acreditavam que para avaliação do ambiente sonoro, seria necessário considerar os inúmeros aspectos humanos envolvidos na percepção sonora (SCHAFFER, 2001). Assim, eles definiram o termo "soundscape", que pode ser traduzido como paisagem sonora, sendo caracterizado como um campo multidisciplinar, em áreas como arquitetura, acústica, psicologia e sociologia (ALETTA et al., 2016).

O conceito de paisagem sonora propõe a avaliação dos sons percebidos em um ambiente, não apenas em sua dimensão física, mas em toda a sua complexidade, assim, são considerados o contexto, a percepção humana e suas correlações. A paisagem sonora leva em conta a avaliação de todos os sons percebidos em um ambiente, considerando toda a sua complexidade (ISO, 2014). Estudos recentes têm mostrado que a avaliação de paisagens sonoras urbanas é muito complexa, pois inúmeros fatores devem ser considerados (GOZALO et al., 2015).

O campo de estudo em paisagem sonora está ganhando força nos últimos anos, em função da necessidade em superar a abordagem do gerenciamento dos ambientes urbanos baseados apenas em políticas de controle do ruído. Com isso, houve um aumento no número de publicações científicas relacionadas à paisagem sonora (ALETTA et al., 2019).

\footnotetext{
${ }^{1}$ Documento de gerenciamento e controle de ruído proposto pela comunidade europeia assinado em 1996 (Zimmerman, 2011)

${ }^{2}$ Diretiva proposta pelo Parlamento Europeu para gerenciamento de ruído no ano de 2002: 2002/49/CE (HOLTZ, 2012) 
Em 2014, foi lançada a primeira norma sobre paisagem sonora, a norma ISO 12913:1 Acoustic Soundscape - Part 1: Definition and conceptual framework (ISO, 2014). Considerada um avanço para o campo de estudo em paisagem sonora, a norma fornece uma definição $e$ estrutura conceitual para a paisagem sonora, apresentando aspectos relevantes, bem como para o planejamento, projeto e gerenciamento da paisagem sonora. Na presente norma, paisagem sonora é definida como "o ambiente acústico percebido, experimento e/ou entendido por uma pessoa ou pessoas, no contexto". A segunda parte da norma foi lançada em 2018, ISO 12913:2 - Acoustic Soundscape - Part 2: Data collection and reporting requirements, e apresenta os procedimentos para coleta de dados e requisitos para aplicação na avaliação da paisagem sonora (ISO, 2018).

Para a avaliação da paisagem sonora podem ser utilizados, por exemplo, modelos preditivos, índices e parâmetros. Os descritores da paisagem sonora são avaliados por meio de processos metodológicos e buscam mensurar como as pessoas percebem o ambiente acústico (ALETTA, 2016). Existe uma grande variedade de métodos utilizados pelos pesquisadores na avaliação da paisagem sonora, a exemplo de observações in loco, entrevistas, questionários, soundwalks ${ }^{3}$, medições acústicas binaurais ${ }^{4}$ e simulações computacionais.

Como exemplo de descritor desenvolvido, Axelsson et al. (2010) desenvolveram um modelo para representar um estudo perceptivo para caracterização de uma paisagem sonora, identificando dois componentes: agradabilidade e agitação. Aletta et al. (2016) apresenta a revisão bibliográfica de pesquisas relacionadas aos descritores ligados à percepção de características acústicas, utilizados para avaliação da paisagem sonora, tais como incômodo do ruído, agradabilidade sonora, similaridade com a música, entre outros.

O campo de pesquisa em paisagem sonora recebeu atenção significativa nos últimos quinze anos. Vale destacar a publicação de uma edição especial sobre paisagem sonora na Acta Acustica e Acustica (Jornal da European Acoustics Association) em 2006 (KANG et al., 2016). De acordo com Kang et al. (2016), a importância da pesquisa em paisagem sonora vem sendo reconhecida por organizações governamentais e órgãos de financiamento na Europa, tendo em vista o potencial de promoção da saúde pública e qualidade de vida, com a realização de projetos de pesquisa, a exemplo da rede Noisefutures, em associação com os projetos Positive Soundscape financiados pelo EPSRC, do Reino Unido (Engineering and Physical Science Research Council).

A compreensão acerca da paisagem sonora auxilia nas estratégias de planejamento urbano, ou seja, no processo de tomada de decisões por parte dos arquitetos, engenheiros e gestores da cidade. Conforme aponta Kang et al. (2016), a alta qualidade da paisagem sonora pode ser obtida por meio de soluções a partir das expectativas dos usuários, de forma que medidas e estratégias podem ser implementadas para reduzir ou eliminar sons indesejáveis. Técnicas de mascaramento do som podem ser adotadas, fazendo uso dos fenômenos psicoacústicos, ou desviar a atenção dos ouvintes para outros sons mais agradáveis, por exemplo.

O presente trabalho visa à realização de estudos prospectivos em bases de patentes e científicas objetivando a avaliação do desenvolvimento de tecnologias ligadas a paisagens sonoras (soundscapes).

\footnotetext{
${ }^{3}$ No método Soundwalk, os usuários do ambiente são conduzidos à caminhada in situ a fim de ouvir o ambiente acústico local, ao término da caminhada, eles podem registrar as impressões a respeito do passeio sonoro, com o preenchimento de um questionário, por exemplo.

${ }^{4}$ Para medições acústicas binaurais são utilizados microfones em cada um dos ouvidos de quem faz a gravação. As medições são gravadas e posteriormente, são reproduzidas.
} 


\section{Metodologia}

A "prospecção tecnológica" pode ser definida como uma forma sistemática de mapear desenvolvimentos científicos e tecnológicos futuros capazes de influenciar de forma significativa uma indústria, a economia ou a sociedade, conforme discutido por Kupfer e Tigre (2004).

Para a realização da prospecção tecnológica foi realizado um levantamento prévio com o objetivo de definir as bases de busca a serem adotadas no estudo. Utilizou-se a palavra-chave (soundscape) como forma de avaliar a capacidade de resgate de documentos no tema em questão. Na Tabela 1 está apresentado o quantitativo de registros encontrados nas bases de busca internacionais: Wipo - Patent Scope, Espacenet (Organização mundial de Propriedade Industrial) e Patentinspiration. Destaca-se que algumas bases possuem campo de indexação de busca diferenciadas, conforme pode ser consultado no campo abrangência de busca. O período de busca foi realizado entre os meses de agosto e setembro de 2019. Para prosseguimento dos estudos, em função do quantitativo dos resultados regatados, optou-se pela base Patente Inspiration.

Tabela 1 - Estudo prévio realizado para escolha do instrumento de busca em bases de patentes

$\begin{array}{ccc}\text { Base } & \text { ABRANGÊNCIA } & \text { QuANTitativo } \\ \text { Wipo - Patent Scope } & \text { Resumo } & 87 \\ \text { Wipo - Patent Scope } & \text { Título } & 20 \\ \text { Wipo - Patent Scope } & \text { Reinvindicação } & 79 \\ \text { Espacenet } & \text { Título } & 12 \\ \text { Espacenet } & \text { Título ou Resumo } & 54 \\ \text { Patente Inspiration } & \text { Titulo } & 36 \\ \text { Patente Inspiration } & \text { Resumo } & 80 \\ \text { Patente Inspiration } & \text { Reinvindicação } & 24 \\ \text { Patente Inspiration } & \text { Título ou Resumo ou Reinvindicação ou Relatório descritivo } & 575\end{array}$

Fonte: Elaborada pelos autores deste artigo (2019)

Como resultado do refinamento da amostra a ser estudada, foram avaliadas as principais classificações das patentes segundo a Classificação Internacional de Patentes - IPC, de forma a delimitar a amostra na categoria mais representativa e adequada ao tema do trabalho (Tabela 2).

Tabela 2 - Subdivisões da classificação IPC relacionadas diretamente com as aplicações soundscape para o tema de interesse

BASE
G06F
E04H
Edificações ou estruturas similares para fins especiais; piscinas para natação
ou recreação; mastros; cercas; tendas ou abrigos provisórios em geral

Fonte: Elaborada pelos autores deste artigo (2019) 
Para a busca de artigos em bases acadêmicas, foram utilizadas como ferramentas as bases Scopus e Web of Science. Utilizou-se a palavra-chave (soundscape) como forma de avaliar a capacidade de resgate de documentos no tema em questão. Na Tabela 3 estão apresentados os quantitativos de registros encontrados nas bases citadas.

Tabela 3 - Levantamento prévio realizado para escolha do instrumento de busca utilizado no estudo em bases acadêmicas

\begin{tabular}{ccc} 
Base & ABranGÊNCIA & Quantitativo \\
Web of Science & Título & 147 \\
Web of Science & Título ou Resumo & 337 \\
Scopus & Título & 1.441 \\
Scopus & Título ou Resumo & 3.279 \\
\hline
\end{tabular}

Fonte: Elaborada pelos autores deste artigo (2019)

\section{Resultados e Discussão}

\subsection{Análise das Patentes}

No primeiro levantamento, utilizando-se a palavra-chave (soundscape), foram resgatados 575 registros na ferramenta Patente Inspiration, com base no termo de busca presente em qualquer um dos seguintes campos dos documentos patentários: título, resumo, quadro reivindicatório ou relatório descritivo. Com este levantamento, foi possível uma primeira análise a respeito do cenário mundial em relação aos tipos e áreas de aplicação das tecnologias protegidas.

Conforme o levantamento prévio apresentado na tabela 1 , devido à possibilidade de busca em campos de indexação mais completos, os resultados dessa seção terão por base a ferramenta Patente Inspiration, com busca dos temos nos campos "Título ou Resumo ou Reinvindicação ou Relatório descritivo". A busca foi realizada com base na data de publicação do pedido de patente, entretanto, devido ao período de sigilo de 18 meses, alguns dados relativos ao ano de 2018 não estão completos.

Analisando-se a distribuição das famílias de patentes pelo IPC, as tecnologias voltadas ao termo "soundscape" estão classificadas em 51 subclasses e se apresentam predominantemente na forma de "Disposições de entrada para transferir dados a serem processados para uma forma capaz de ser manipulada pelo computador", conforme identificado no Gráfico 1. 
Gráfico 1 - Distribuição das principais famîlias de patentes com busca "soundscape" por classificação IPC Quantidade de registros por IPC

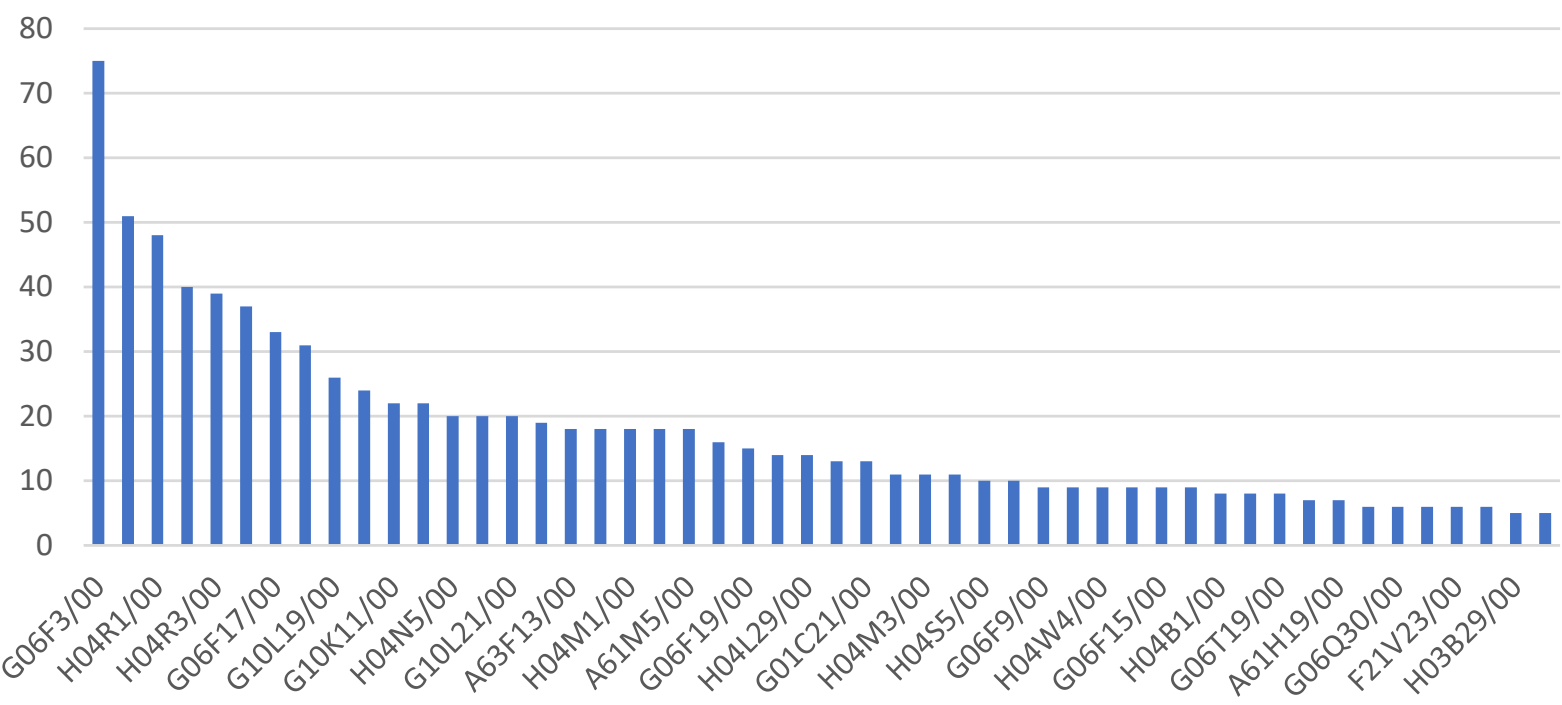

Fonte: Elaborado pelos autores deste artigo (2019)

Os Estados Unidos detêm o maior número de pedidos de patentes depositadas (317), seguido por Holanda (46), Japão (44), Reino Unido (37), Canadá (30), Alemanha (19), Finlândia (15), Singapura (12), França (12), Israel (10), Bélgica (9), Suíça (8), França(8) e China (8), dentre outros países em menor destaque, conforme pode ser observado no Gráfico 2. Não foram encontrados registros de proteção por patente da tecnologia "soundscape" no Brasil, também confirmado a partir da base de Dados do INPI.

Gráfico 2 - Países com depósitos de patentes com tecnologias relacionas ao termo "soundscape"
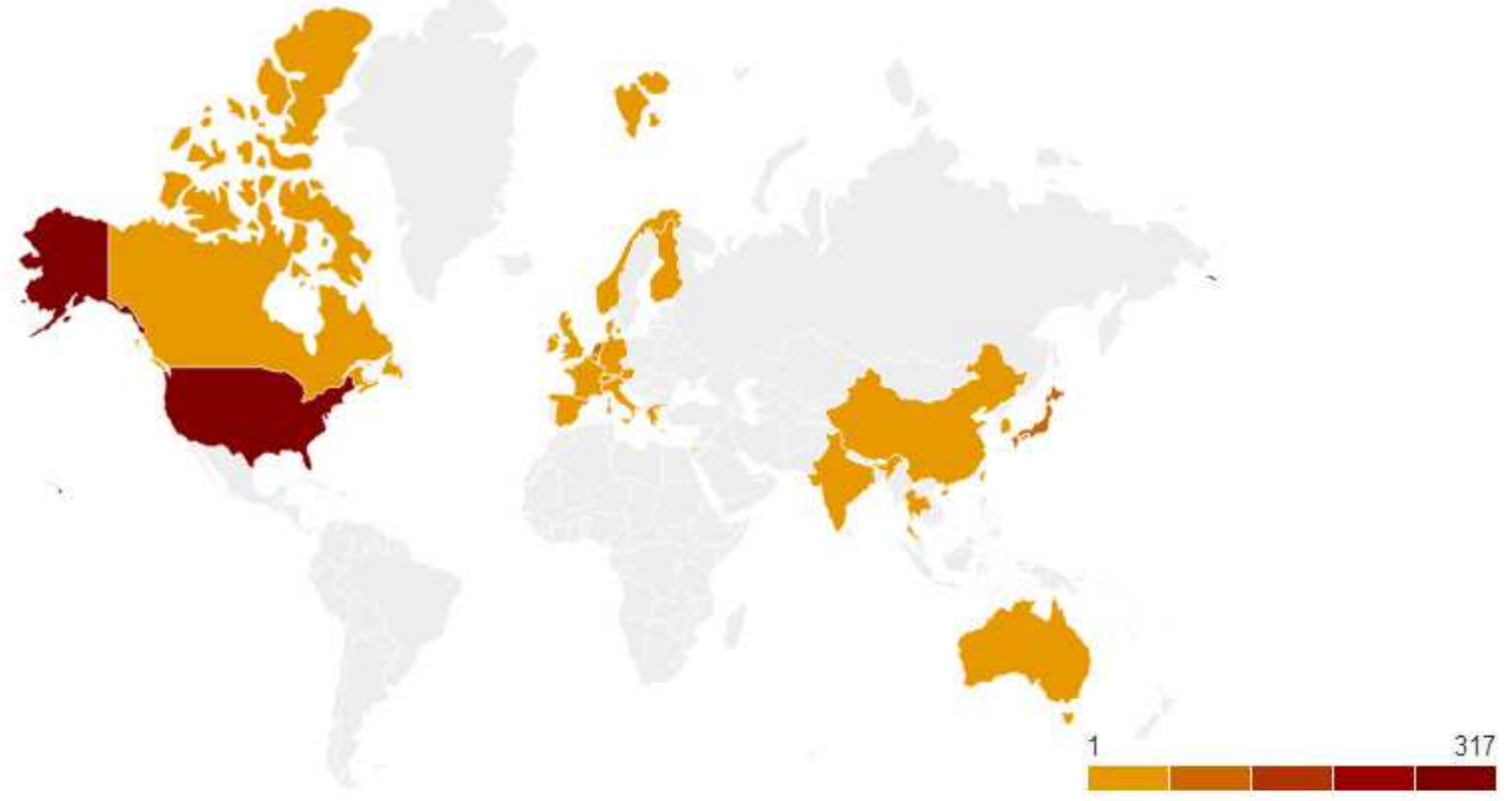

Fonte: Elaborado pelos autores deste artigo - Baseado em dados retirados na base Patente Inspiration (2019) 
A análise da evolução temporal considerando as datas de depósito das patentes, conforme apresentado no Gráfico 3, revelou que desde 1994 foram registrados pedidos de patentes de tecnologias ligados ao termo "soundscape". Nos anos de 2001, 2003 e 2006, o número de patentes depositadas apresentou crescimento representativo. A partir de 2013, o número de depósitos passou a apresentar um crescimento exponencial, chegando ao pico em 2017.

Gráfico 3 - Evolução temporal das patentes relacionadas a tecnologias soundscape

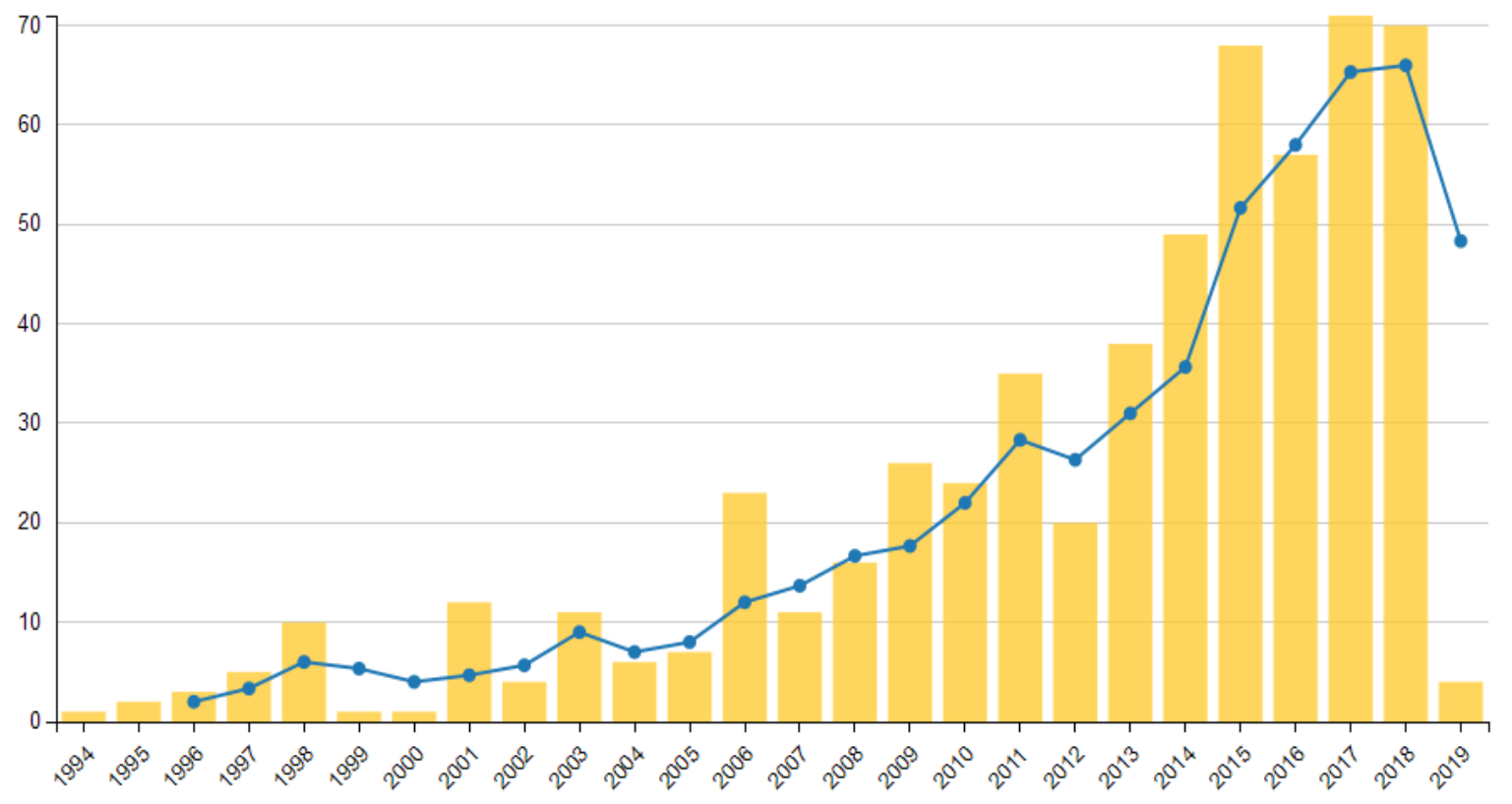

Fonte: Elaborado pelos autores deste artigo (2019)

Nos últimos cinco anos, tem-se observado predominância de depósito de patentes ligadas às classificações IPC A61B5/00 (Medição com finalidades de diagnóstico), H04W4/00 (Serviços especialmente adaptados para as redes de comunicação sem fio) e H04R5/00 (Disposições estereofônicas), conforme pode ser consultado no Gráfico 4.

Gráfico 4 - Depósito de patentes por IPC relacionadas a tecnologias soundscape

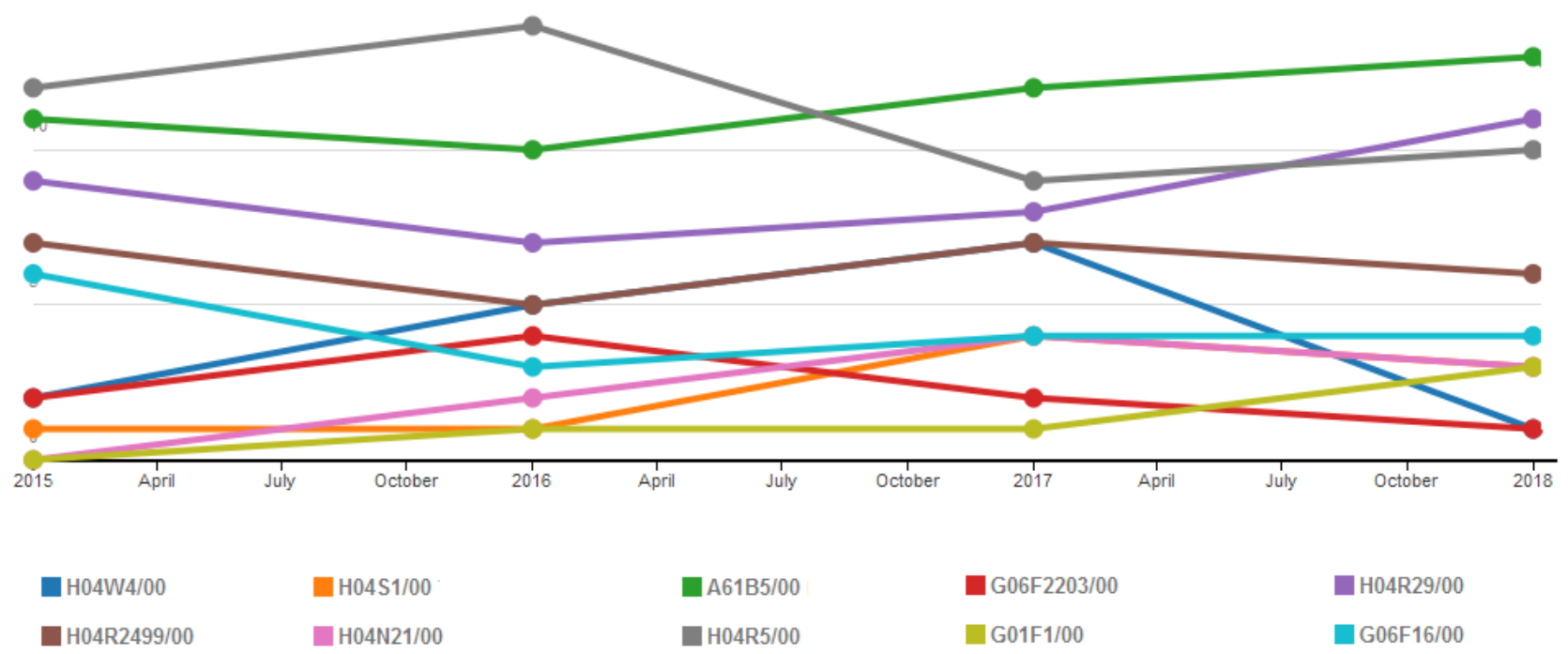

Fonte: Elaborado pelos autores deste artigo (2019) 
A análise revela que dentre os 575 registros de publicação de patentes na base Patente Inspiration relativos ao termo soundscape, apenas 269 pedidos foram concedidos. $\mathrm{O}$ índice de $46,78 \%$ de pedidos de patentes ainda em análise, reforça ainda mais o recente interesse pelo desenvolvimento de tecnologia citada. A Tabela 4 apresenta os 10 maiores depositantes detentores de patentes relativas a tecnologias soundscape.

Tabela 4 - Os dez maiores detentores de patentes ligadas a tecnologias soundscape

\begin{tabular}{cc} 
DePOSITANTE & Quantidade De PATENTE CONCEDidas \\
KONINKL PHILIPS ELECTRONICS NV & 11 \\
DEKA PRODUCTS LP & 11 \\
IHEAR MEDICAL INC & 9 \\
NORRIS GLEN A & 9 \\
MONKEYMEDIA INC & 8 \\
MICROSOFT TECHNOLOGY LICENSING LLC & 7 \\
DISNEY ENTPR INC & 6 \\
DOPPLER LABS INC & 6 \\
LYREN PHILIP SCOTT & 6 \\
MICROSOFT CORP & 5 \\
\hline
\end{tabular}

Fonte: Elaborada pelos autores deste artigo - Baseado em dados retirados na base Patente Inspiration (2019)

Ao realizar a análise de evolução temporal do depósito de patentes ligadas a tecnologias soundscape restritas aos IPC G06F, E04H e H04R (conforme descrito na tabela 2), verifica-se um quantitativo de 262 depósitos de patentes, cuja evolução temporal pode ser observada no Gráfico 5.

Gráfico 5 - Evolução temporal das patentes com IPC G06F, E04H ou H04R relacionadas a tecnologias soundscape

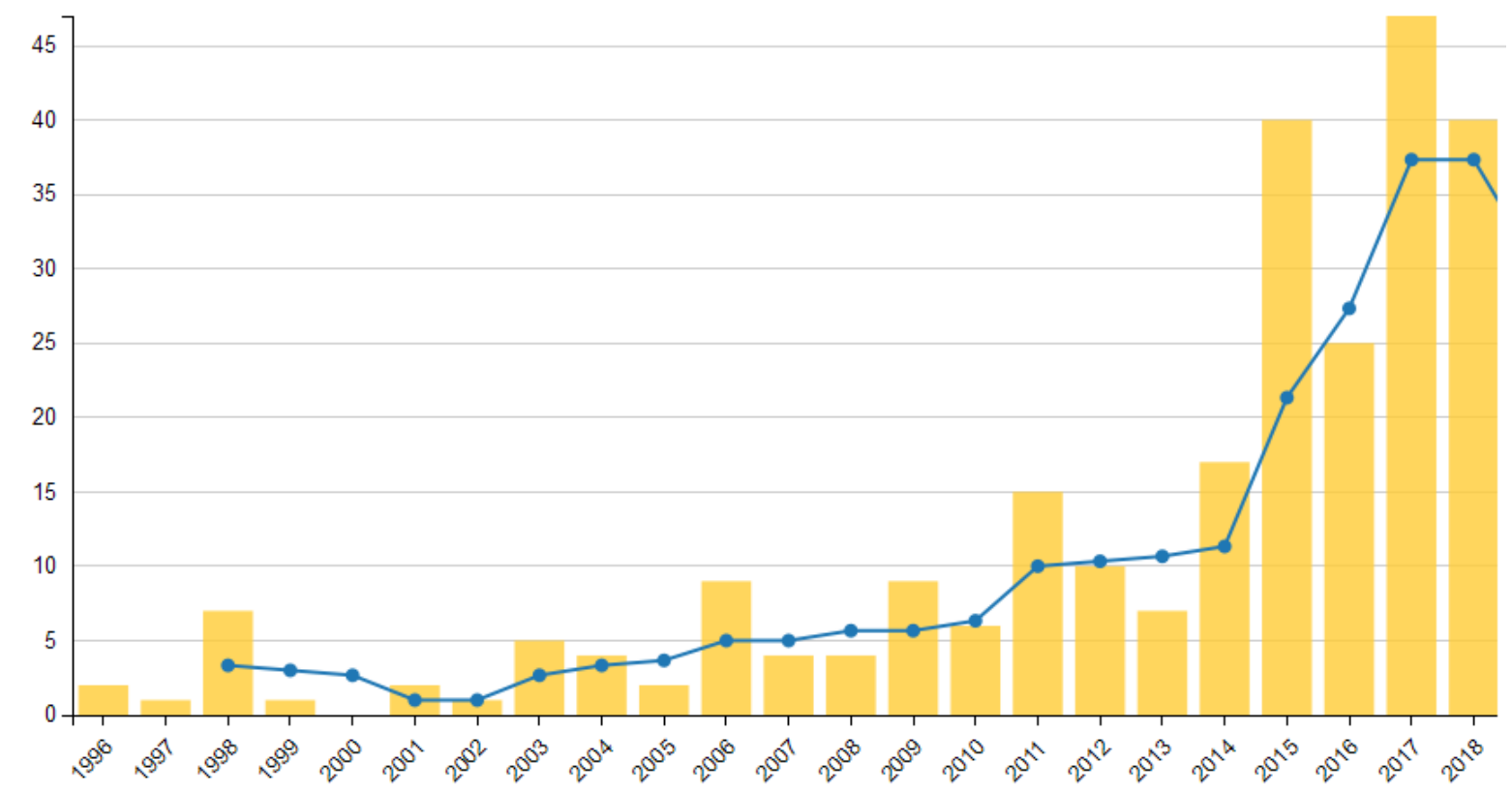

Fonte: Elaborado pelos autores deste artigo (2019) 
Entre as patentes ligadas a tecnologias soundscape relacionadas aos IPC G06F, E04H e H04R, verifica-se que do total de 262 depósitos, apenas 144 foram concedidas, o que indica que $45,03 \%$ dos pedidos de patentes ainda estão pendentes de análise. Tal fato comprova que a busca por proteção patentária da referida tecnologia é extremamente recente. O Gráfico 6 apresenta a evolução temporal das patentes com IPC G06F, E04H ou H04R concedidas nos últimos 10 anos, mostrando a forte predominância do mercado norte-americano.

Gráfico 6 - Evolução temporal das patentes com IPC G06F, E04H ou H04R concedidas nos últimos 10 anos relacionadas a tecnologias soundscape

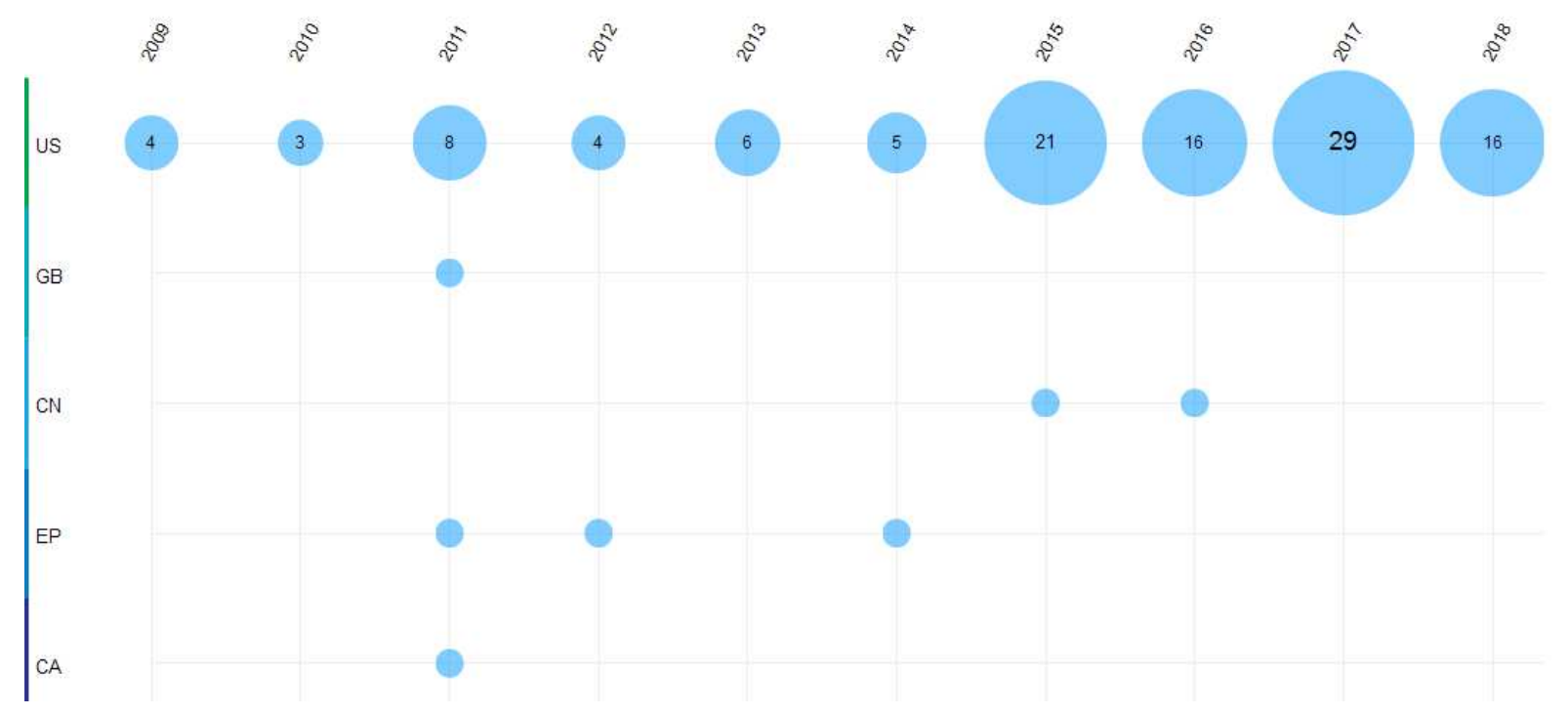

Fonte: Elaborado pelos autores deste artigo (2019)

\subsection{Artigos Científicos}

Para a busca de artigos científicos na base de dados da plataforma Scopus, foi utilizada a palavra-chave (soundscape), resultando em 3278 registros. Os dados obtidos foram tratados de forma a possibilitar uma avaliação geral em termos de área temática, evolução histórica e país de publicação. Os resultados dessa seção serão focados com base em dados da base Scopus, tendo em vista o retorno de maior número de trabalhos indexados ao campo de busca, conforme levantamento prévio apresentado na Tabela 1.

Após o refinamento dos dados pelas palavras-chaves e agrupando-se o volume de artigos por áreas comuns, foi possível identificar as principais temáticas abordadas nos artigos científicos, as quais são apresentadas na Tabela 5. 
Tabela 5 - Principais temáticas abordadas nos artigos científicos voltados a tecnologia (soundscape)

$\begin{array}{ccc}\text { Temáticas } & \text { Artigos } & \text { PerCeNTUAL } \\ \text { Física e Astronomia } & 1146 & 35,07 \% \\ \text { Artes e humanidades } & 828 & 25,34 \% \\ \text { Ciências sociais } & 628 & 19,22 \% \\ \text { Ciências da Computação } & 572 & 17,50 \% \\ \text { Engenharias } & 458 & 14,01 \% \\ \text { Ciências ambientais } & 452 & 13,83 \% \\ \text { Demais áreas } & 5 \% & 24,97 \%\end{array}$

Fonte: Elaborada pelos autores deste artigo - Baseado em dados extraídos da base Scopus (2019)

A evolução histórica da publicação dos artigos revela que desde 1985 são realizadas publicações relacionando o tema soundscape, mas somente a partir de 2003, se observa o início de um crescimento mais significativo no número de publicações, com destaque para o crescimento exponencial projetado a partir de 2009, com pico no ano de 2017, conforme pode ser observar no Gráfico 7.

Gráfico 7 - Evolução histórica das publicações de artigos voltados à temática soundscape

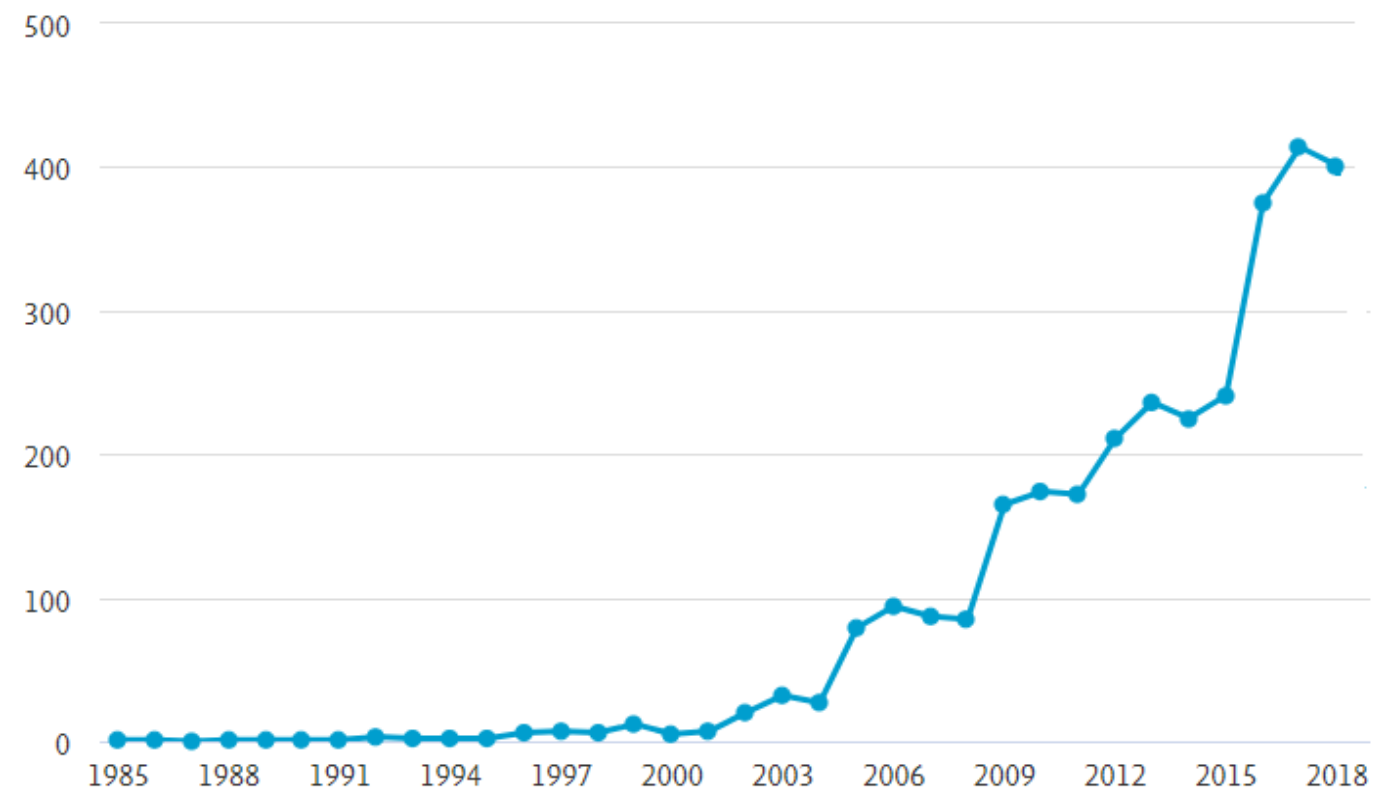

Fonte: Elaborado pelos autores deste artigo (2019)

No que se refere ao país de publicação dos artigos, observa-se no Gráfico 9 que os Estados Unidos (710), Reino Unido (618), China (206), Alemanha (188), França (182), Itália (182) e Canadá (179), Austrália(179) e China (162) representam juntos 72,24\% das publicações da área. Embora os autores dos artigos nesta temática tenham uma tendência de publicarem em revistas nacionais pela natureza inerente ao tema, é importante salientar que a indicação do país utilizada neste gráfico é referente ao país de origem do periódico. Destaca-se o Brasil, com 68 publicações, ocupando a $17^{a}$ posição. 
Gráfico 8 - Os países que mais publicaram artigos voltados à temática soundscape

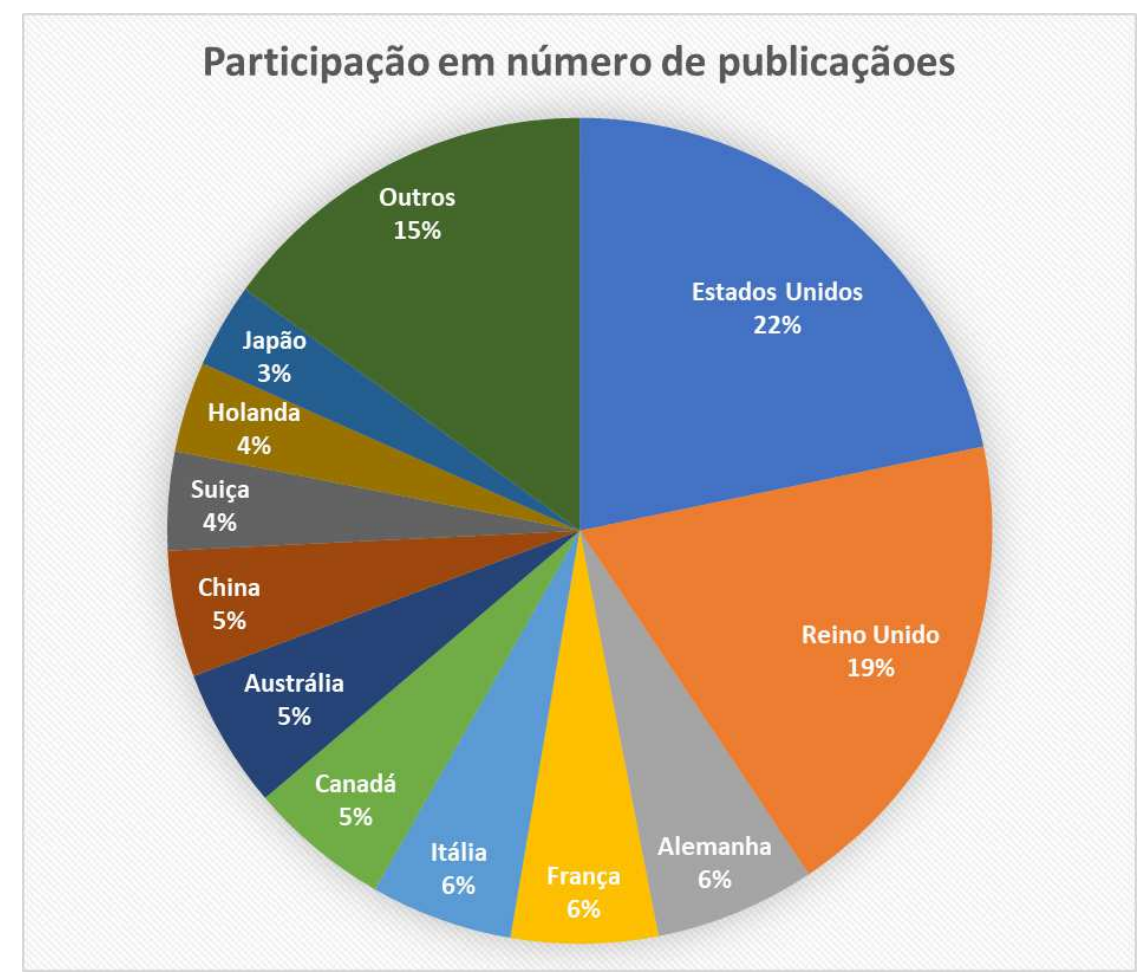

Fonte: Elaborado pelos autores deste artigo (2019)

Ao analisar as instituições que mais publicaram artigos científicos relativos à temática soundscape, observa-se a predominância absoluta das universidades, que ocupam as 10 primeiras posições neste ranking, diferentemente do que foi demonstrado com a análise das maiores organizações depositantes de patentes, que são empresas, em sua maioria, da área de tecnologia, conforme apresentado no Gráfico 9.

Gráfico 9 - As instituições que mais publicaram artigos voltados à temática soundscape

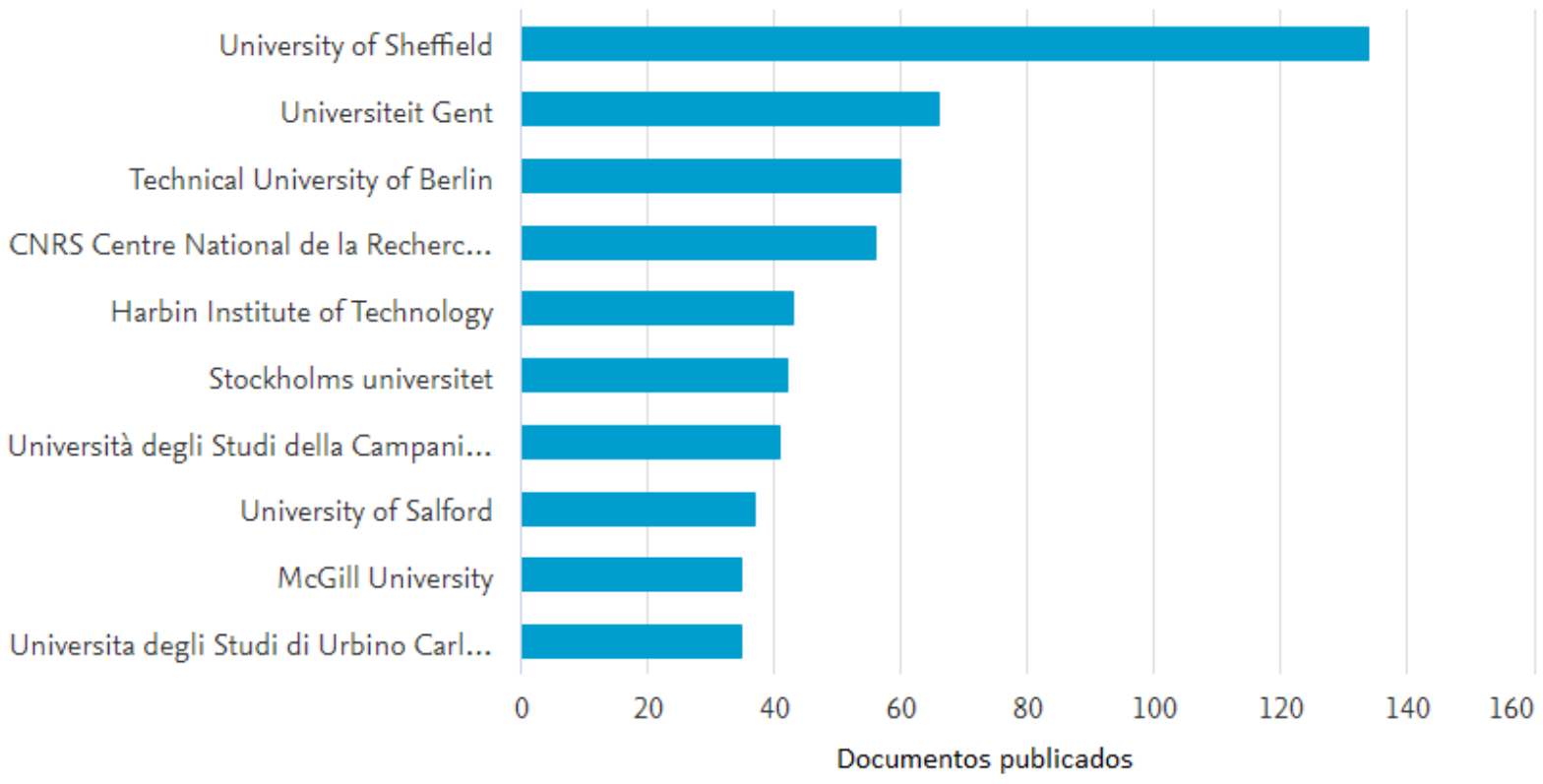

Fonte: Elaborado pelos autores deste artigo (2019) 
Em relação ao tipo de publicação, verifica-se predominância de artigos em revistas (1.474), publicações em conferências (1.225), capítulos de livros (235), artigos de revisão (164), artigos de revisão em conferências (164) e livros (55), conforme apresentado no Gráfico 10.

Gráfico 10 - Principais tipos de publicação voltados à temática soundscape

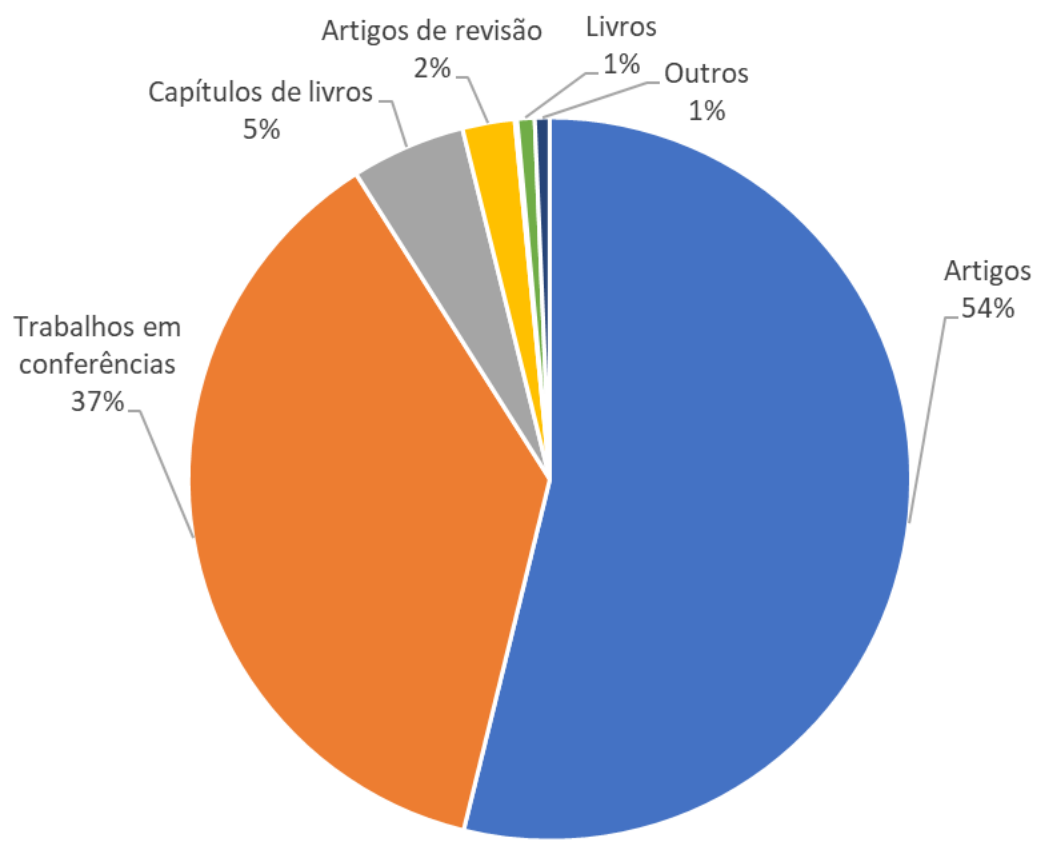

Fonte: Elaborado pelos autores deste artigo (2019)

Ao refinar a busca para a avaliação de publicações acadêmicas ligadas a tecnologias de soundscape aplicadas ao planejamento urbano (soundscape AND urban AND Plann*), foram resgatados 899 documentos. O número de artigos com a temática tem aumentando consideravelmente desde 2009, conforme pode ser observado no Gráfico 11.

Gráfico 11 - Evolução histórica das publicações de artigos voltados à temática soundscape ligada ao planejamento urbano

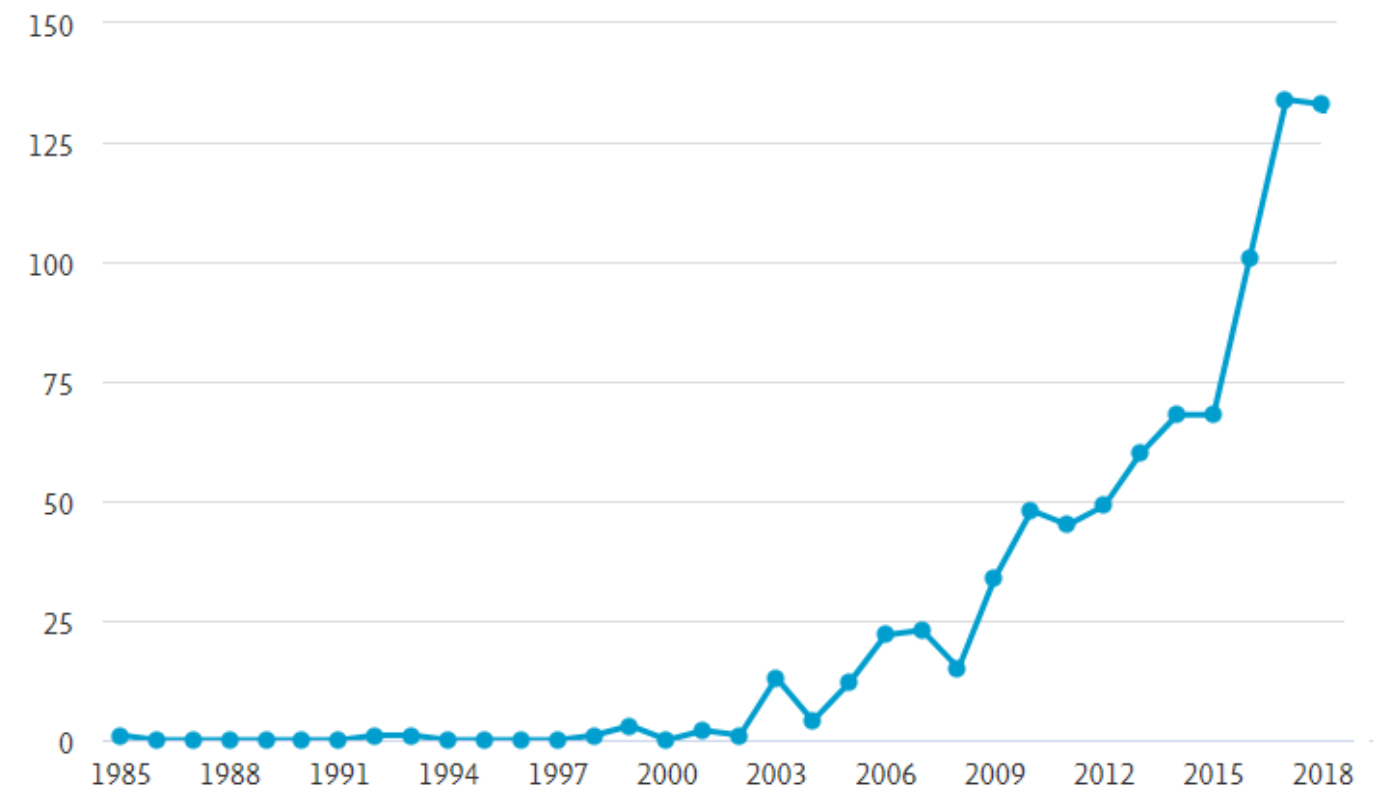

Fonte: Elaborado pelos autores deste artigo (2019) 
Quanto ao tipo de publicação, com o refinamento da busca para as tecnologias voltadas ao planejamento urbano, verifica-se predominância de artigos em revistas (54\%), publicações em conferências (37\%), capítulos de livros (5\%), artigos de revisão (2\%).

A Tabela 6 apresenta os principais veículos de publicação de artigos científicos voltados à tecnologia (soundscape) na área de planejamento urbano, que são distribuídos de forma não concentrada entre revistas indexadas e publicações em conferências internacionais.

Tabela 6 - Principais temáticas abordadas nos artigos científicos voltados a tecnologia (soundscape)

\begin{tabular}{ccc} 
FonTE DE PUBLICAÇão & $\begin{array}{c}\text { QUANTIDA- } \\
\text { DE }\end{array}$ & $\begin{array}{c}\text { PERCEN- } \\
\text { TUAL }\end{array}$ \\
Applied AcousticsShow preview & 42 & $4,7 \%$ \\
$\begin{array}{c}\text { Proceedings Of The Inter Noise 2016 45th International Congress And Exposition } \\
\text { On Noise Control Engineering Towards A Quieter FutureShow preview for }\end{array}$ & 27 & $3,0 \%$ \\
$\begin{array}{c}\text { Inter Noise 2017 46th International Congress And Exposition On Noise } \\
\text { Control Engineering Taming Noise And Moving QuietShow preview for }\end{array}$ & 26 & $2,9 \%$ \\
Landscape And Urban PlanningShow preview for & 26 & $2,9 \%$ \\
Journal Of The Acoustical Society Of AmericaShow preview for & 25 & $2,8 \%$ \\
Acta Acustica United With AcusticaShow preview for & 24 & $2,7 \%$ \\
International Journal Of Environmental Research And Public HealthShow preview for & 22 & $2,4 \%$ \\
\hline
\end{tabular}

Fonte: Elaborada pelos autores deste artigo - Baseado em dados extraídos do Scopus/Elsevier (2019)

Analisando-se as instituições que mais publicaram artigos científicos relativos à temática soundscape ligado ao planejamento urbano, observa-se a predominância absoluta das universidades, que ocupam as 10 primeiras posições neste ranking, conforme apresentado no Gráfico 12.

Gráfico 12 - Origem de artigos voltados à temática soundscape ligados ao planejamento urbano

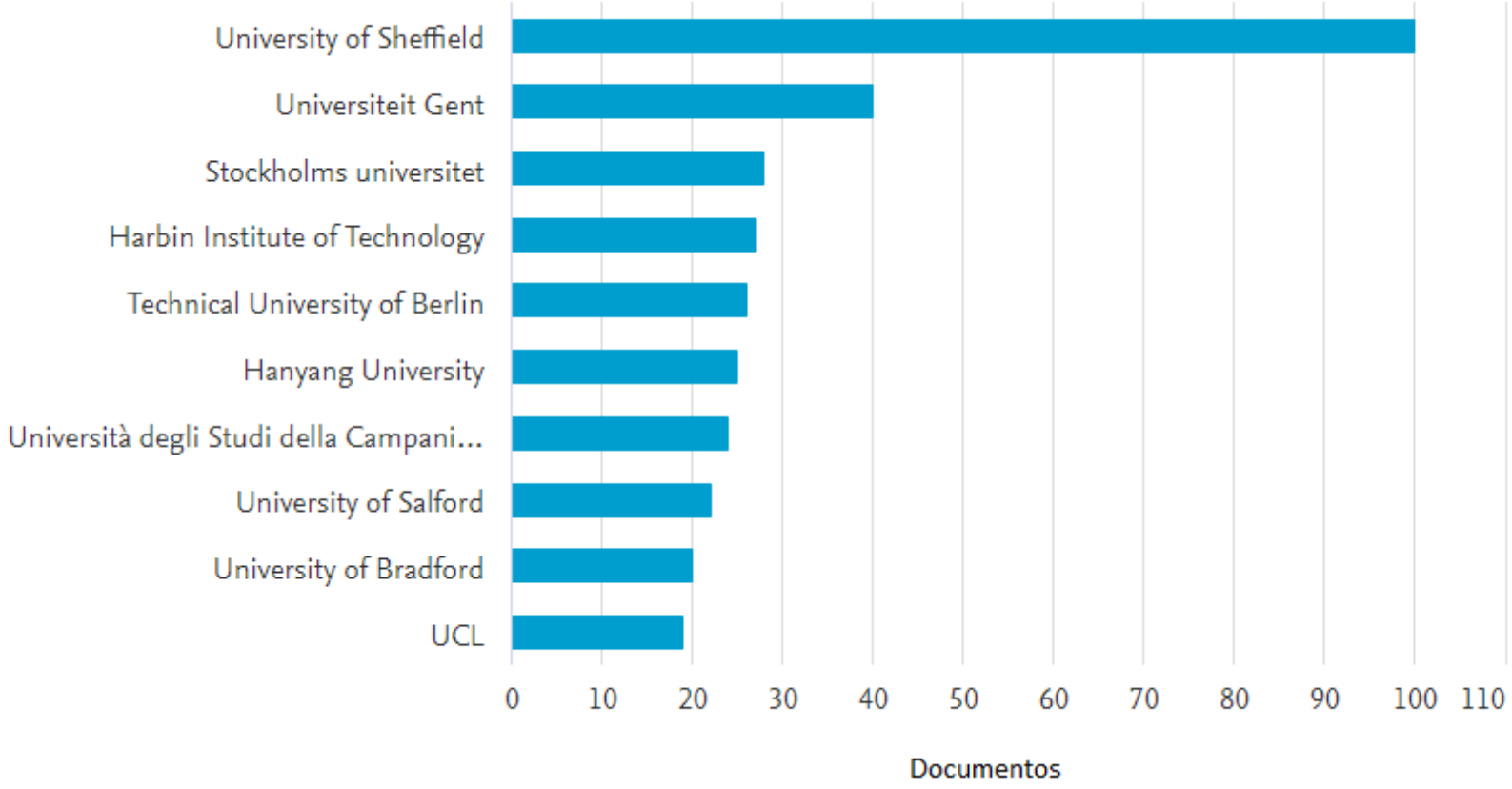

Fonte: Elaborado pelos autores deste artigo (2019) 
O Gráfico 13 apresenta a relação dos principais pesquisadores que mais publicaram artigos científicos relativos a temática soundscape ligado ao planejamento urbano, com destaque para Kang. J, professor da University of Sheffield.

Gráfico 13 - Principais pesquisadores no campo de soundscape aplicada ao planejamento urbano

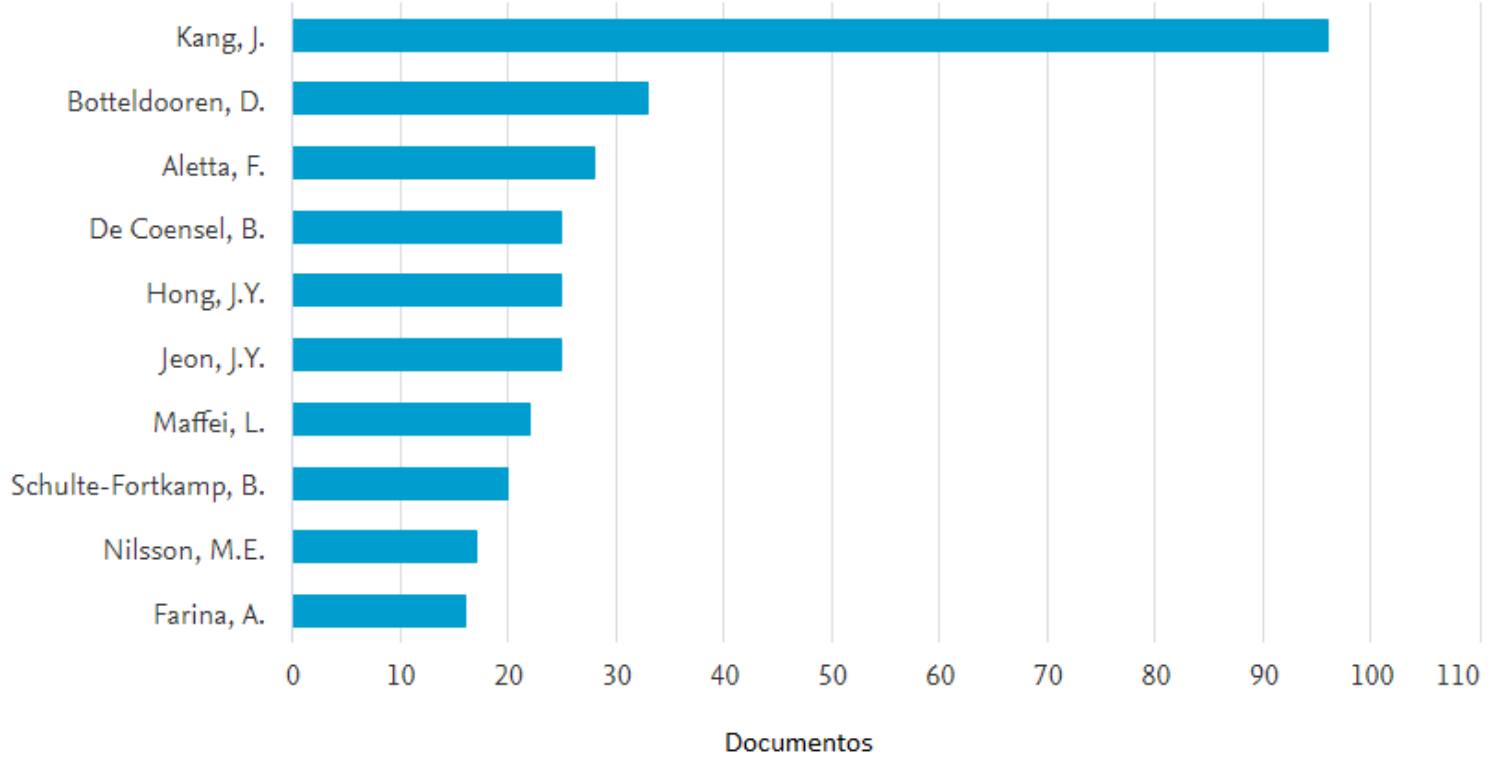

Fonte: Elaborado pelos autores deste artigo (2019)

Em relação ao país de origem dos autores de publicação dos artigos na temática citada anteriormente, observa-se no Gráfico 14 a liderança do Reino Unido, seguido por Estados Unidos, China, Itália, Suíça e Alemanha. Esse resultado pode ser explicado pelo fato de pesquisadores importante, a exemplo de Kang, J. e Aletta, F, atuarem na University of Sheffield, situada no Reino Unido.

Gráfico 14 - Países de origem de artigos voltados à temática soundscape.ligado ao planejamento urbano

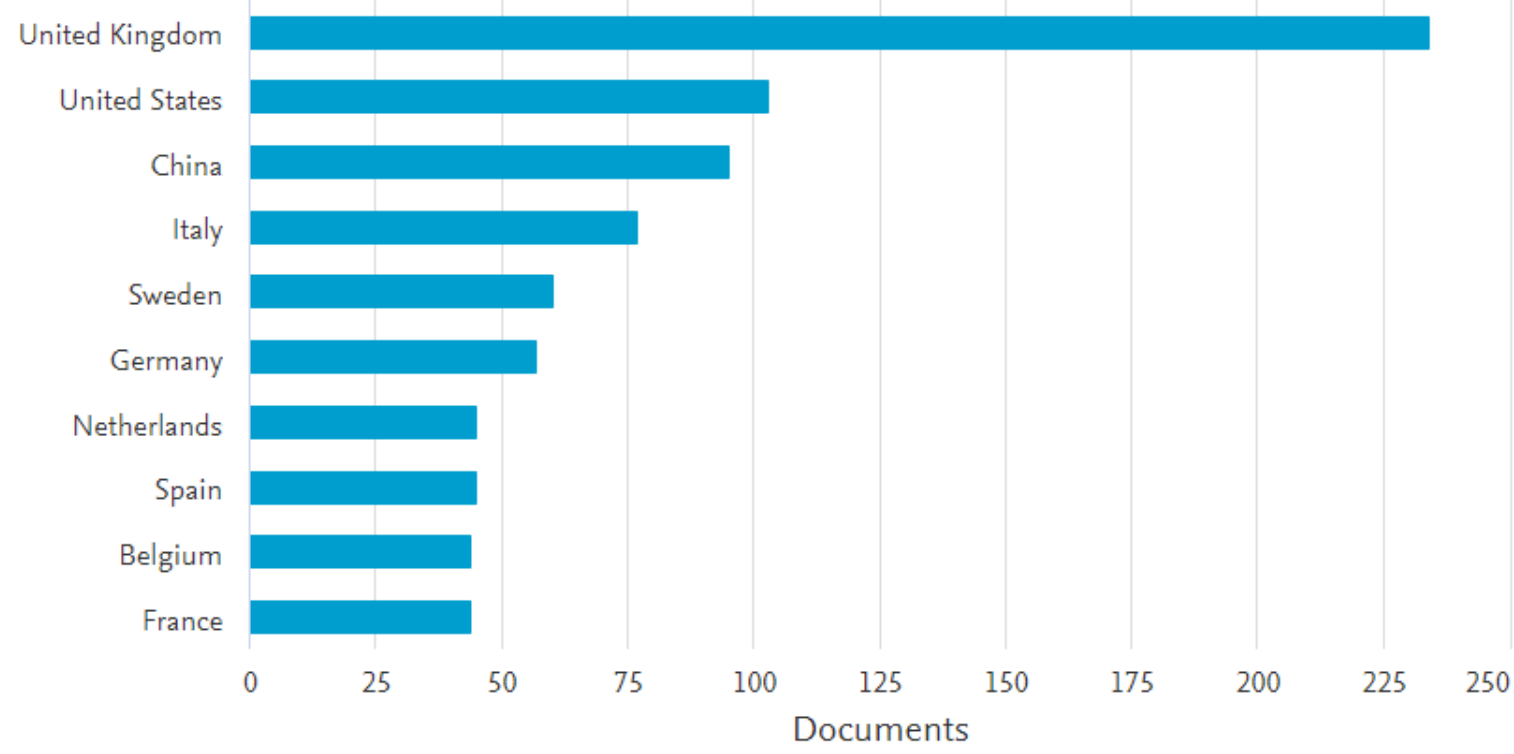

Fonte: Elaborado pelos autores deste artigo (2019) 


\section{Considerações Finais}

Os resultados da prospecção tecnológica em bases de patentes reforçaram que os desenvolvimentos ligados a temática paisagem sonora (soundscape) são relativamente novos, tendo em vista que $44,4 \%$ dos depósitos de patentes estão concentrados nos últimos 5 anos. Tal motivação pode estar relacionada com a publicação da primeira parte da norma ISO 12913:1 - Acoustic Soundscape - Part 1: Definition and conceptual framework (ISO, 2014), ocorrida em 2014.

Os Estados Unidos, Holanda, Japão, e Reino Unido, se destacam respectivamente como os maiores depositantes de patentes com tecnologias voltadas ao soundscape. No entanto, no que diz respeito a patentes que envolvem a aplicação direta de soundscape no planejamento urbano, o Reino Unido lidera o depósito de patentes. Tal fato também é observado em relação à produção científica, conforme resultados apresentados.

A produção científica atingiu o percentual máximo no ano de 2018, que coincidiu com a publicação da segunda parte da norma ISO 12913:2 - Acoustic Soundscape - Part 2: Data collection and reporting requirements, a qual apresenta os procedimentos para coleta de dados e requisitos para aplicação na avaliação da paisagem sonora (ISO, 2018).

A produção técnico-científico no Brasil na corrente área de estudo se apresentou praticamente inexpressiva, distante das grandes potências haja vista que não há produtos ou métodos patenteados, bem como é observado uma baixa produção científica relacionado ao tema, ocupando apenas o $17^{0}$ lugar na posição mundial. Tal informação mostra uma lacuna nessa área de estudo no país, sendo necessário avançar diante da importância do tema para o planejamento urbano. Com base nos resultados obtidos, fica claro que os estudos prospectivos são ferramentas que podem contribuir significativamente para a formulação das políticas públicas nacionais.

\section{Referências}

ALETTA, F. et al. Exploring the compatibility of "Method A" and "Method B" data collection protocols reported in the ISO/TS 12913-2:2018 for urban soundscape via a soundwalk. Applied Acoustics, [S. l.], v. 155, p. 190-203, maio 2019. Elsevier BV. https://doi.org/10.1016/j. apacoust.2019.05.024 Disponível em: https://www.sciencedirect.com/science/article/pii/ S0003682X1930026X. Acesso em: 14 ago. 2019.

ALETTA, F; KANG, J.; AXELSSON, O. Soundscape descriptors and a conceptual framework for developing predictive soundscape models. Landscape And Urban Planning, [S. 1.], v. 149, p. 6574, maio 2016. Elsevier BV. http://dx.doi.org/10.1016/j.landurbplan.2016.02.001. Disponível em: https://www.sciencedirect.com/science/article/pii/S0169204616000074. Acesso em: 01 jul. 2019.

AXELSSON, Östen; NILSSON, Mats.; BERGLUND, Birgitta. A principal components model of soundscape perception, J. Acoust. Soc. Am., v. 128, n. 5, p. 2836-2846, nov. 2010.

CAIN, R.; JENNINGS, P.; POXON, J. The development and application of the emotional dimensions of a soundscape. Applied Acoustics, [S. l.], v. 74, p. 232-239, 2013. Elsevier BV. doi:10.1016/j. apacoust.2011.11.006. 
GOZALO, G. et al. Relationship between objective acoustic indices and subjective assessments for the quality of soundscapes. Applied Acoustics, [S. l.], v. 97, p.1-10, abril 2015. Elsevier BV. http:// dx.doi.org/10.1016/j.apacoust.2015.03.020 Disponivel em: https:/https:/www.sciencedirect.com/ science/article/pii/S0003682X1500105X?via\%3Dihub. Acesso em: 01 maio. 2019.

HARVIE,, J.; CONLAN, N.; WEI, W.; SIDDALL, M. How loud is too loud? noise from domestic mechanical ventilation systems. International Journal of Ventilation, v. 18, n. 4, p. 303-312, 2019. DOI: 10.1080/14733315.2019.1615217.

HOLTZ, M. C. de B. Avaliação qualitativa da paisagem sonora de parques urbanos. Estudo de caso: Parque Villa Lobos, em São Paulo. 118 f. Dissertação (Mestrado em Arquitetura e Urbanismo) - Faculdade de Arquitetura e Urbanismo, Programa de Pós-Graduação em Arquitetura e Urbanismo, Universidade de São Paulo, São Paulo, 2012.

INTERNATIONAL ORGANIZATION FOR STANDARDIZATION. ISO 12913. Acoustics Soundscape. Part 1: Definition and conceptual framework, ISO 12913:1. 2014.

INTERNATIONAL ORGANIZATION FOR STANDARDIZATION. ISO 12913. Acoustics Soundscape. Part 2: Data collection and reporting requirements, ISO 12913:2. 2018.

KANG, J. et al. Ten questions on the soundscapes of the built environment. Building and Environment, [S. l.], v. 108, p. 284-294, nov. 2016. Elsevier BV. http://dx.doi.org/10.1016/j. buildenv.2016.08.011. Disponível em: https:/www.sciencedirect.com/science/article/pii/ S0360132316303067. Acesso em: 15 maio 2019.

KUPFER, D.; TIGRE, P. B. Modelo SENAI de prospecção: documento metodológico. Capítulo 2: prospecção tecnológica. In: ORGANIZACION INTERNACIONAL DEL TRABAJO CINTERFOR. Papeles de La Oficina Técnica. Montevideo: OIT/CINTERFOR, 2004.

SCHAFER, M. A Afinação do mundo - uma exploração pioneira pela história passada e pelo atual estado do mais negligenciado aspecto do nosso ambiente: a paisagem sonora. São Paulo: Editora UNESP. 2001.

World Health Organization (WHO). In: BERGLUND, B.; LINDVALL, T.; SCHWELA, D. H.; GOH, K. T. (ed.). Guidelines for community noise. Geneva. 1999.

ZIMMERMAN, T. R. C. Monitoring residential noise for prospective home owners and renters Lecture Notes in Computer Science (including subseries Lecture Notes in Artificial Intelligence and Lecture Notes in Bioinformatics), 6696 LNCS, pp. 34-49, DOI: 10.1007/978-3-642-21726-5_3. 2011.

\section{Sobre os Autores}

\section{Jordana Teixeira da Silva}

E-mail: jordana.teixeiraa@gmail.com

Graduação em Arquitetura e Urbanismo - UFAL (2011), Mestrado em Arquitetura e Urbanismo pela UFAL (2014). Atualmente é professora do Instituto Federal de Alagoas.

Endereço profissional: Instituto Federal de Alagoas, PI/IFAL, Palmeira dos Índios, AL. CEP: 57608-180. 


\section{João Paulo Lima Santos}

E-mail: jpls@lccv.ufal.br

Graduação em Engenharia Civil pela UFAL (2005), Mestrado em Engenharia Civil pela UFRJ (2008) e Doutorado em Engenharia Civil pela UFRJ (2011).

Endereço profissional: Campus A.C Simões, LCCV/UFAL, Cidade Universitária, Maceió, AL. CEP: 57072-970.

\section{Maria Lucia Gondim da Rosa Oiticica}

E-mail:mloiticica@hotmail.com

Graduação em Arquitetura e Urbanismo pela UFAL (1981), Mestrado em Environmental Design And Engineering - University of London (1983) e Doutorado em Engenharia Civil, Arquitetura e Urbanismo pela UNICAMP.

Endereço profissional: Campus A.C Simões, Faculdade de Arquitetura/UFAL, Maceió, AL. CEP: 57072-970.

\section{Edilson Ponciano de Lima}

E-mail: edilsonponciano@yahoo.com

Mestre em Propriedade intelectual e Transferência Tecnológica para a Inovação - Profnit / UFAL(2019). Graduação (Bacharelado) em Sistemas de Informação pela Faculdade Estácio de Alagoas (2008).

Endereço profissional: Campus A.C Simões, PROFNIT/UFAL, Cidade Universitária, Maceió, AL. CEP: 57072-970. 